\title{
Therapy-Related Acute Myeloid Leukemia
}

National Cancer Institute

\section{Source}

National Cancer Institute. Therapy-Related Acute Myeloid Leukemia. NCI Thesaurus. Code C8252.

An acute myeloid leukemia arising as a result of the mutagenic effect of chemotherapy agents and/or ionizing radiation. (WHO, 2001) 